\section{¿Cuándo es necesario realizar confirmación histológica en un paciente con sospecha de metástasis encefálica?}

\section{Estimado Editor:}

La confirmación histopatológica constituye un tópico controvertido en pacientes con sospecha de metástasis encefálica. La obtención de material puede realizarse a través de resección quirúrgica de una de las lesiones o mediante una biopsia estereotáxica. Para algunos autores la primera constituye el proceder preferido porque facilita en un solo tiempo el diagnóstico y el tratamiento, es recomendada en enfermos sin neoplasia primaria conocida y lesión única resecable ${ }^{1}$. La biopsia estereotáxica se reserva para aquellos pacientes con lesiones inaccesibles, mal estado general o comorbilidad severa y lesión única no resecable sin neoplasia primaria conocida. Si la lesión intracraneal es asintomática, carece de efecto de masa y la lesión extracraneal permite realizar la biopsia, debe procederse a esto último $^{2}$. Si no es posible realizar biopsia de las lesiones extracraneales, la biopsia estereotáxica o resección quirúrgica de la lesión intracraneal está indicada ${ }^{1}$.

Un grupo de facultativos respalda la toma de muestra sustentados en que, cuando existen una o más lesiones cerebrales y un cáncer sistémico conocido, del 5 al 11\% de los casos las lesiones cerebrales no son metastásicas, correspondiendo a abscesos cerebrales, neoplasias primarias, granulomas o hemorragias ${ }^{1,3}$. Otros plantean que la biopsia estereotáxica cerebral presenta mayor índice diagnóstico que la biopsia de la lesión primaria pero mayor mortalidad y evitan este proceder basados en la evidencia de un cáncer conocido ${ }^{1,4,5}$. Esta conducta conlleva un posible sesgo, que incluso podría justificar ciertos casos reportados con elevada supervivencia. Por otra parte, constituyen procederes menos invasivos, reduciendo la morbilidad y complicaciones asociadas.
En pacientes con lesiones múltiples sin neoplasia primaria conocida se ha recomendado la realización de biopsia estereotáxica de una de las lesiones o cirugía de la lesión más accesible, de la que presente efecto de masa, mayor tamaño o localizaciones de riesgo como región temporal. En ocasiones pueden ser resecadas en conjunto lesiones muy cercanas. Por otra parte, si existen otras lesiones extracraneales sospechosas de ser metastásicas el diagnóstico se realizará a través de la biopsia de la lesión extraneural más accesible y de menor riesgo con el fin de evitar la biopsia o cirugía cerebral ${ }^{2}$. Condición especial constituye la presencia de una lesión quística, donde debe tenerse en consideración el grosor de la cápsula y el domo de la misma para optimar las posibilidades de lograr tomar una muestra útil ${ }^{6}$, si no, quizás sea más conveniente la planificación de una remoción total de la lesión. Para algunos autores, la excepción para realizar procedimientos invasivos diagnósticos serían las situaciones como: neoplasia primaria conocida (lo cual se contrapone al planteamiento de que podrían no ser lesiones metastásicas), clínica compatible con la evolución neoplásica y lesiones múltiples de neoplasias primarias como melanoma o cáncer de pulmón ${ }^{2}$.

¿Se debe tener en cuenta al tomar la decisión el diagnóstico histopatológico de la neoplasia primaria? Algunos tumores primarios tienden a metastatizar más que otros. En orden de frecuencia se encuentran el melanoma, pulmón y carcinoma de células renales. Otras lesiones como el cáncer de próstata y de estómago rara vez metastatizan a encéfalo. Para otros autores el tumor con mayor propensión es el cáncer testicular. Aunque el cáncer de mamas no posee esta elevada propensión a metastatizar a encéfalo, su elevada incidencia hace que sea la segunda causa de metástasis cerebral después del cáncer de pulmón ${ }^{7}$. Dados estos elementos, podría sugerirse la biopsia en casos de neoplasias con baja frecuencia de metástasis a encéfalo.

De gran utilidad sería el diseño de estudios de autopsias a pacientes previamente tratados con modalidades de radioterapia, con el objetivo de confirmar el diagnóstico presuntivo en la mesa de Morgagni. 
Por el momento, cabe a buen juicio del profesional actuante mediante una valoración individualizada, proceder en beneficio del paciente.

\section{Referencias bibliográficas}

1. Ross DA. Stereotactic Brain Biopsy or Bronchoscopic/Transthoracic Needle Biopsy for Diagnosis of Metastatic Cancer Presenting Simultaneously in Lung and Brain: A Comparison of Safety and Efficacy. Cancer and Clinical Oncology 2012; 1 (2): 1927-4866.

2. Rabadán AT, Diez B, Martínez AM, Antico J, Saidón P, Christiansen S, et al. Consenso para el tratamiento de las metástasis cerebrales. Rev argent neurocir 2006; 20 (4): 1532-850.

3. Voorhies RM, Sundaresan N, Thaler HT. The single supratentorial lesion. An evaluation of preoperative diagnostic tests. J Neurosurg 1980; 53:364-8.

4. Patil CG, Pricola K, Garg SK, Bryant A, Black KL. Whole brain radiation therapy (WBRT) versus WBRT and radiosurgery for the treatment of brain metastases. Cochrane Database of Systematic Reviews 2010, Issue 6. [DOI: 10.1002/14651858.
CD006121.pub2].

5. Kondziolka D, Niranjan A, Kano H, Flickinger JC. Gamma Knife Radiosurgery of Other Brain Metastases. In: Lunsford LD, Kim DG, Lunsford LD (eds): Current and Future Management of Brain Metastasis. Prog Neurol Surg. Basel, Karger, 2012: 25; 190-200.

6. Toyokawa G, Toyozawa R, Inamasu E, Kojo M, Morodomi Y, Shiraishi Y, et al. Cystic brain metastasis of non-small-cell lung cancer successfully controlled with Ommaya reservoir placement. Int Canc Conf J 2013; 2: 89-92.

7. Caballero García J, de Mendoza Amat JH, Cruz García O, Montero González T, Felipe Morán A. Características de la metástasis intracraneal en 14 321 autopsias realizadas en el Hospital "Dr. Luis Díaz Soto”, La Habana (1962-2011). Rev Cubana Neurol Neurocir. [Internet] 2013 [citado el 7 de julio de 2013]; 3 (2): 132-8. Disponible en: http:// www.revneuro.sld.cu.

Joel Caballero G. ${ }^{1}$ y Orlando Cruz G. ${ }^{2}$ ${ }^{1}$ Residente de 4 to año de Neurocirugía.

${ }^{2}$ Doctor en Ciencias Médicas. Especialista de Segundo Grado en Neurocirugía. Investigador y Profesor Titular.
Correspondencia:

Dr. Joel Caballero García.

Calle 23 esquina L edificio 301 apto C-12.

Vedado. La Habana. Cuba.

Teléfono: 8329629.

E-mail: joelc@infomed.sld.cu. 